\title{
Gross Anatomical Study on the Prenatal Develop- ment of the Penis in Goat (Capra hircus)
}

\section{M.M. Farooqui, C.P. Sharma, Archana Pathak and Ajay Prakas}

Pt. Deen Dayal Upadhyaya Veterinary University-Mathura-281001, India

\section{Abstract}

A study was conducted to record the morphogenesis of penis in prenatal goat. Seventy embryos/ foeti ranged from 23days to full term were collected from the gravid uteri of apparently healthy goats, obtained from a local abattoir. The approximate age of embryos/foeti was computed and was divided into five groups. At 23 days of gestation, the external genitalia appeared in the form of a cone shaped projection known as genital tubercle, ventral to the cloacal opening and flanked by pelvic limbs. At 30 days of gestation, the tubercle became elongated and directed ventrally where it was bounded on either side by urethral plates. With the increase in gestation period, the genital tubercle became more erected and the urethral plates became thicker to form the urethral folds. At 42 days of gestation the tubercle began to migrate along the abdominal wall towards the umbilicus. The rounded tip of the tubercle had a constriction in its ventral side indicating the beginning of formation of future glans. An anogenital raphe was formed at 48 days of gestation. At 55 days of gestation all the three muscles viz; bulbuspongiosus, ischiocavernosus and retractor penis were distinct. At 72 days of gestation the glans reached closed to the umbilicus. The proximal part of the sigmoid flexure was formed on 78th day of gestation. Both the curves of flexure were formed on 98 days of gestation. On 65th days onwards all the three parts of penis i.e. root, body and glans were distinct.

Keywords: Morphogenesis; Penis; Goat.

\section{Introduction}

Sex determination can be divided in three distinct phases. The first phase at the time of fertilization sex is determined genetically by the chromosomal complement of fertilizing spermatozoa. The second phase, during embryonic development this genetic information is translated to gonadal sex, which determines the growth of either testis or ovary from an early indifferent gonad. In the third 
Prenatal development of goat's penis

phase phenotypic sex determination begins in foetal or early postnatal life in which endocrine products of gonads direct the differentiation of accessory sex duct (Loofler and Koopman, 2002).

On perusal of literature it is found that very meager work has been carried out on the prenatal development of the penis in domestic animal, hence an attempt has been made to study the development of the penis in prenatal goat development.

\section{Material and Methods}

A study was conducted on the 70 embryos/ foeti ranged from 23 days to full term collected from the gravid uteri of apparently healthy goat, obtained from a local abattoir. Each foetus was measured for its crown rump length in centimeters with the help of nylon tape (Harvey 1959) and weighed in grams on analytical balance. The approximate age was computed according to the formula derived by Singh et. al. (1979). These embryos/foeti were divided into five groups.

\begin{tabular}{|c|c|c|c|}
\hline S. No. & Group & Age & $\begin{array}{c}\text { Weight of } \\
\text { foetus }(\mathbf{g})\end{array}$ \\
\hline 1 & Group-I & 0-30days & --- \\
\hline 2 & Group-II & $\begin{array}{c}31-60 \\
\text { days }\end{array}$ & 0.86 to 18.9 \\
\hline 3 & Group- III & $\begin{array}{c}61-90 \\
\text { days }\end{array}$ & 56 to 200.0 \\
\hline 4 & Group- IV & $\begin{array}{c}91-120 \\
\text { days }\end{array}$ & 284 to 435.8 \\
\hline 5 & Group- V & $\begin{array}{c}121-\text { till full } \\
\text { term }\end{array}$ & 675 to \\
& & \multicolumn{2}{|c}{} \\
\hline
\end{tabular}

\section{Farooqui et al.,}

The sex of the foeti was determined by the appearance of genital tubercle in the form of epithelial tag, genital swelling, anogenital raphae up-to mid stage of group II. In the other groups the sex was identified by the development of the penis and the scrotal sac. The fine dissection was made to observe the development of the penis in the foeti. The topographic location and shape of the penis was recorded. The data was put for statistical analysis (Snedecor and Cochran 1980).

\section{Results and Discussion}

At 23 day of gestation (12.00 mm $\mathrm{CRL})$, the external genitalia appeared in the form of vaguely outlined, cone shaped projection, the genital tubercle. It was located ventral to cloacal opening flanked by the pelvic limb buds on either side (Fig. 1). Noden and de Lahunta (1985) reported similar findings in cow embryos at $12 \mathrm{~mm}$ stage. At 30 days of gestation $(16 \mathrm{~mm}$ $\mathrm{CRL})$, the tubercle became elongated $(1 \mathrm{~mm}$ long) and was vertically directed. Ventrally, it had a groove, which was bounded on either side by thickening throughout its length, the urethral plates. The cranial end of the tubercle was swollen and had an oval shape. The elongation of the tubercle at $16 \mathrm{~mm} \mathrm{CRL}$ stage was also in partial agreement with the previous findings of Glenister (1956) in pig embryos, where he observed swollen cranial end of the tubercle in slightly older embryos (18 mm). This may possibly 
atrributed to the species difference. The observations regarding the length of the tubercle were in total agreement with the findings of Glenister (1956) at this stage. However, Inomata et al. (1982) observed the genital tubercle in bovine foetuses of less than $20 \mathrm{~mm} \mathrm{CRL}$ in the midline between the umbilical cord and the tail as small elevation. Arey (1966) described this structure at 7 th week of gestation in human embryos. The beginning of the appearance of the urethral plates and a groove on the ventral aspect at $16 \mathrm{~mm} C R L$ stage was in harmony with the earlier reports of Glenister (1956) in pig embryos. However, the process of development of the urethral plates started from the base of the cloaca to the tip of the tubercle which was in agreement to the earlier reports of Glenister (1956) who reported that the appearance of these plates started from the base of the phallus and then extended distally toward the tip.

The genital tubercle at the age of 17 $\mathrm{mm}$ CRL was $1.2 \mathrm{~mm}$ long, more elongated and erect as compared to $16 \mathrm{~mm}$ CRL stage. The medial borders of the urethral plates became thicker to form the urethral folds. At this stage, the genital swellings appeared as poorly defined, rounded structures on either side of the urethral plates. At 42 days of gestation, the tubercle began to migrate along the abdominal wall towards the umbilicus and measured $1.6 \mathrm{~mm}$ in length (Fig.2). The cranial migration of the genital tubercle as being caused by lengthening of the axial parts of the organ occurred under the perineal skin. Rounded tip of the tubercle had a constriction in its ventral side indicating the beginning of the formation of future glans. The primordium of glans appeared on the dorsolateral aspect of the glans at 48 days of gestation. The genital swelling became more conspicuous at this time. Glenister (1956) also observed the depression in $20 \mathrm{~mm}$ pig embryos near the tip of the phallus and referred it as the site of in growth of surface epithelium to meet the most cranial part of the urethral plate.

At 48 day of gestation, the urethral folds of the opposite sides began to unite indicating the beginning of formation of the ano-genital raphae. The process was started caudally and preceded towards the tip of the tubercle. Similar observations were recorded by Glenister (1956) in pig embryos and referring it as perineal raphae. At this stage, the genital tubercle curved caudad and was $1.9 \mathrm{~mm}$ long. It further migrated towards umbilicus and was more markedly curved. Its distal half was observed to begin to set at right angle. The genital swellings were placed behind the tubercle due to its shifting towards umbilicus. The genital swellings became hemispherical as compared to oval at 42 days stage, which was an indic tion of the formation of future scrotal pouch. 
Prenatal development of goat's penis

At 49 days of gestation, the phallus measured $2.0 \mathrm{~mm}$ in length and presented similar features as on 48 day except that the ano-genital raphe was distinct due to the complete fusion of the urethral folds (Fig.3). At this stage, the ano-genital distance was $7.0 \mathrm{~mm}$ long. The glans became harder than 48th day stage and was slightly elevated from the genital swellings. These swellings became elongated and obliquely directed, while the distal end of the scrotum became pointed. A shallow groove (scrotal raphe) appeared in between two swellings. At 50 days of gestation, the ano-genital raphe became more distinct (Fig.4). The phallus was 3.0 $\mathrm{mm}$ long and the ano-genital distance was $12 \mathrm{~mm}$ long. At 55 day, the free portion of the genital tubercle was more raised above the level of the scrotum and became more erect as compared to 50 days of gestation. The ano-genital distance measured $13 \mathrm{~mm}$ in length at this stage. The length of the phallus measured 4.5 $\mathrm{mm}$. The glans was distinct. The urethral process began to appear at this stage from left side of glans, which slowly turned to right side. The free portion of the phallus became more erect and its lower portion was at right angle close to the abdominal wall. A raphe was observed just below the glans, which was directed backward. At 55 day of gestation, all the three muscles of the penis viz; bulbospongiosus, ischio cavernosus and retractor penis were discernible clearly. The

J. Vet. Anat.
Farooqui et al.,

M. Retractor penis was attached to the body of the penis behind the developing scrotal sac. The suspensory ligament was placed at the level of union of crura in the form of mesenchymal tissue.

At 60th day of gestation, the elongated glans reached near the umbilicus (Fig.5) and on 72 days it was close to the umbilicus at its future normal location.

At 71 days of gestation, a very slight concavity was observed in the body of the penis just behind the scrotal sac, which became deeper on 78th day leading to the formation of proximal part of the sigmoid flexure. At 78th day of gestation, the proximal curve became more distinct and a distal curve appeared at a very short distance of the previous one (proximal curve). At 98 day of gestation, both the curves were distinct and the area between the two curves was elongated and a sigmoid flexure became more conspicuous (Fig.6). The process of development of the sigmoid flexure was almost completed by the 123 day of gestation (Fig.7).

In third month of gestation, 65th day onwards all the parts root, body and glans became conspicuous. Various biometrical parameters of the penis could be recorded easily from group III onwards. The data is summarized in Table (1). Analysis of the data revealed that the length of the crura increased significantly from group (III) to (V). It became just double 
$(0.952 \pm 0.065)$ in group $(\mathrm{V})$ from the values of group III $(0.416 \pm 0.064)$. The maximum growth took place in the last trimester of the gestation.

The total length of the penis from union of the crura to the tip of the glans penis was lowest in group (III) when compared with groups (IV) and (V). It increased as development proceeded. Thus the data revealed that there was a positive correlation between the growth of the penis and growth of the foetus i.e. age.

The length of the body of the penis between two the convexities of sigmoid flexure was highly distinct in groups (IV) and (V). However, at the end of 3rd month of gestation it was recorded lowest. Near the full term stage, an average $0.78 \mathrm{~cm}$ from the penis length was involved in the formation of sigmoid flexure. This observation was in contrast to the earlier reports of Gupta et al. (1982). The penis was straight without sigmoid flexure in neonate buffaloes.

The data also revealed that the part below the attachment of retractor penis muscle grew faster than the part above this muscle to the union of crura. There was gradual increase in the length of the body of penis from union of the crura to the attachment of retractor penis muscle. The highest values were recorded in group (V) (121 to till full term). The length of the glans penis was increasing from group (II) to group (V).

The maximum diameter of the penis was recorded at the union of the crura followed by the convexities of the sigmoid flexure and the glans. The lowest diameter was observed just prior to the glans. The diameter of the penis increased progressively as the age of the foetus advanced.

\section{References}

Arey L. B. (1966): Developmental Anatomy - A textbook and laboratory manual of embryology. 7th ed. Philadelphia and London,W.B. Saunders Company.

Glenister, T.W. (1956): The development of penile urethra in the pig. Journal of Anatomy, 90: 461-477.

Harvey, E.B. (1959): Aging and foetal development. In: Reproduction in Domestic Animals (Eds.), Cole, H.H. and Eupps, P.T., I ${ }^{\text {st }}$ Ed., Vol. I, Academic Press Inc., New York, pp. 461466.

Inomata, T.; Eguchi, Y.; Yamamoto, M.; Asari, M. and Kano, Y. (1982): Development of the external genitalia in bovine fetuses. Jpn. J. Vet. Sci., 44: 489-96.

Loffler, $\mathrm{K} A$ and Koopman, $\mathrm{P}$. (2002): Charting the course of ovarian development in vertebrates. International Journal of Developmental Biology. 46:503-510.

Noden, D.M. and de Lahunta, A. (1985): The Embryology of Domestic 
Animals. $1^{\text {st }}$ Edition, Williams and Wilkins Company, Baltimore, U.S.A., pp. 322-340.

Singh, Y.; Sharma, D.N. and Dhingra, L.D. (1979): Morphogenesis of the testis in goat. Indian Journal of Animal Sciences, 49(11): 925-931.
Snedecor, G.W. and Cochran, W.G. (1980): Statistical Methods. $6^{\text {th }}$ ed. Indian Edition, Oxford and IBH Publishing Company, New Delhi.

\section{Corresponding author:}

M.M. Farooqui

Email: mmfarooqui64@gmail.com

Table (1): Morphometry (Mean \pm SE) of foetal penis in goat

\begin{tabular}{|c|c|c|c|c|c|}
\hline \multirow[b]{2}{*}{ Group } & \multicolumn{2}{|c|}{ Weight of foetus (mm) } & \multirow[b]{2}{*}{ Parameters } & \multirow[b]{2}{*}{$\begin{array}{l}\text { Range } \\
(\mathrm{cms})\end{array}$} & \multirow[b]{2}{*}{$\begin{array}{c}\text { Mean + SE } \\
(\mathrm{cms})\end{array}$} \\
\hline & Range & $\begin{array}{l}\text { Mean + } \\
\text { SE }\end{array}$ & & & \\
\hline $\begin{array}{c}\text { III } \\
(61-90 \\
\text { days })\end{array}$ & $\begin{array}{c}56 \text { to } 200.0 \\
\mathrm{~g}\end{array}$ & $\begin{array}{c}127.325 \pm \\
0.00266\end{array}$ & $\begin{array}{l}\text { 1. Length of crus penis (Length of penis from ischial arch to union of crura) } \\
\text { 2. Length of penis from union of crura to the tip of the glans penis } \\
\text { 3. Length of penis from union of two crura to the point of attachment of ret. penis } \\
\text { muscle } \\
\text { 4. Length of penis between upper and lower convexity of sigmoid flexure } \\
\text { 5. Length of penis between attachment of ret. penis muscle to the beginning of the glans } \\
\text { 6. Total length of the glans penis } \\
\text { 7. Diameter at the union of crura } \\
\text { 8. Diameter between the proximal and distal convexity } \\
\text { 9. Diameter beneath the distal curve and glans } \\
\text { 10. Diameter at the glans }\end{array}$ & $\begin{array}{c}0.23-0.63 \\
1.74-3.80 \\
0.44-1.50 \\
- \\
1.31-1.70 \\
0.22-0.60 \\
0.15-0.30 \\
- \\
0.075-0.22 \\
0.10-0.24\end{array}$ & $\begin{array}{r}0.416+0.0640 \\
2.758+0.3291 \\
0.938+0.1756 \\
* \\
- \\
1.573+0.0698 \\
0.353+0.0715 \\
0.196+0.0276 \\
- \\
0.0145+0.0281 \\
0.156+0.0237\end{array}$ \\
\hline $\begin{array}{l}\text { IV } \\
\text { (91-120 } \\
\text { days) }\end{array}$ & 284 to $435.8 \mathrm{~g}$ & $\begin{array}{c}335.7866 \pm \\
29.1745\end{array}$ & $\begin{array}{l}\text { 1. Length of crus penis (Length of penis from ischial arch to union of crura) } \\
\text { 2. Length of penis from union of crura to the tip of the glans penis } \\
\text { 3. Length of penis from union of two crura to the point of attachment of ret. penis } \\
\text { muscle } \\
\text { 4. Length of penis between upper and lower convexity of sigmoid flexure } \\
\text { 5. Length of penis between attachment of ret. penis muscle to the beginning of the glans } \\
\text { 6. Total length of the glans penis } \\
\text { 7. Diameter at the union of crura } \\
\text { 8. Diameter between the proximal and distal convexity } \\
\text { 9. Diameter beneath the distal curve and glans } \\
\text { 10. Diameter at the glans }\end{array}$ & $\begin{array}{l}0.31-0.75 \\
4.20-5.75 \\
1.525-2.00 \\
0.30-0.50 \\
2.05-3.50 \\
0.20-0.55 \\
0.20-0.43 \\
0.13-0.33 \\
0.15-0.33 \\
0.16-0.28\end{array}$ & $\begin{array}{c}0.492+0.0832 \\
4.856+0.2794 \\
1.8052+0.0877 \\
0.38+0.0379 \\
2.72+0.2349 \\
0.404+0.0651 \\
0.336+0.0375 \\
0.252+0.0349 \\
0.23+0.0304 \\
0.247+0.0223\end{array}$ \\
\hline $\begin{array}{c}\mathrm{V} \\
\text { (121-till } \\
\text { term) }\end{array}$ & $\begin{array}{c}675 \text { to } 1720.34 \\
\mathrm{~g}\end{array}$ & $\begin{array}{c}1277.6757 \pm \\
155.49\end{array}$ & $\begin{array}{l}\text { 1. Length of crus penis (Length of penis from ischial arch to union of crura) } \\
\text { 2. Length of penis from union of crura to the tip of the glans penis } \\
\text { 3. Length of penis from union of two crura to the point of attachment of ret. penis } \\
\text { muscle } \\
\text { 4. Length of penis between upper and lower convexity of sigmoid flexure } \\
\text { 5. Length of penis between attachment of ret. penis muscle to the beginning of the glans } \\
\text { 6. Total length of the glans penis } \\
\text { 7. Diameter at the union of crura } \\
\text { 8. Diameter between the proximal and distal convexity } \\
\text { 9. Diameter beneath the distal curve and glans } \\
\text { 10. Diameter at the glans }\end{array}$ & $\begin{array}{l}0.83-1.20 \\
6.00-7.95 \\
2.30-2.90 \\
0.70-0.90 \\
2.90-3.78 \\
0.50-1.12 \\
0.32-0.62 \\
0.25-0.42 \\
0.20-0.39 \\
0.25-0.40\end{array}$ & $\begin{array}{c}0.952+0.0651 \\
7.104+0.349 \\
2.63+0.1113 \\
0.78+0.0352 \\
3.36+0.1862 \\
0.83+0.1135 \\
0.448+0.0664 \\
0.32+0.0370 \\
0.282+0.0373 \\
0.312+0.0359\end{array}$ \\
\hline
\end{tabular}

* Recorded only in one foetus of 88 day's gestation. 


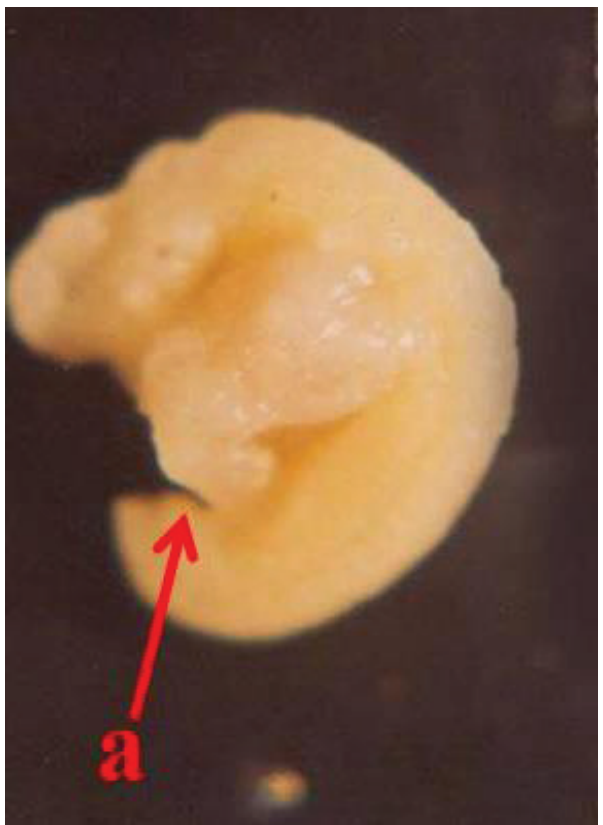

Fig (1): Photograph of a 23-day-old (1.2 cm CRL) goat embryo showing genital tubercle (a) located ventral to anal orifice.

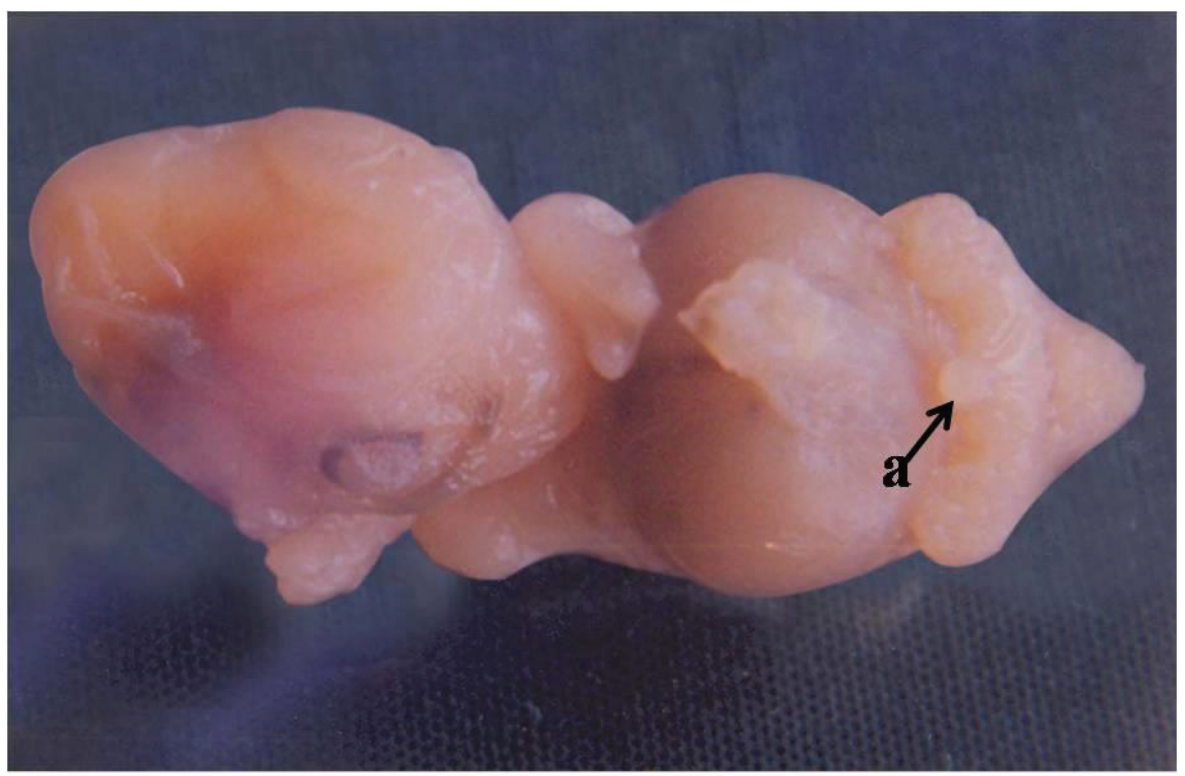

Fig (2): Photograph of a 42-day-old goat foetus (ventral view) showing migration of genital tubercle (arrow) towards umbilicus (a). 


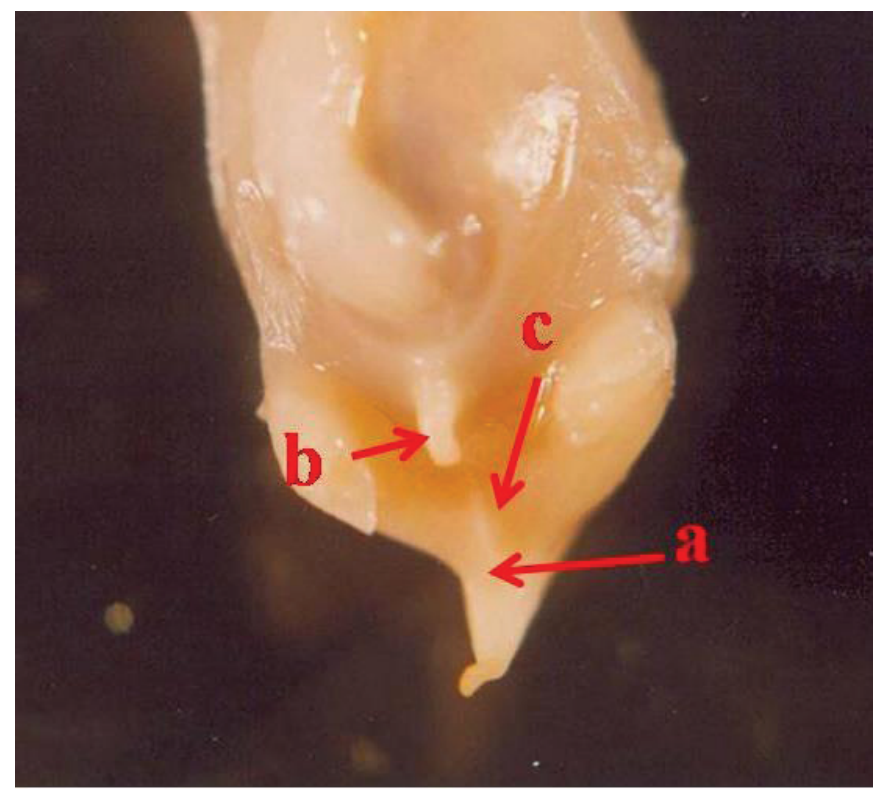

Fig (3): Photograph of a 49-day-old goat foetus (ventral view) showing further migration of the penis towards umbilicus ano-genital raphe (a), caudally curved phallus (b) and scrotal swellings (c).

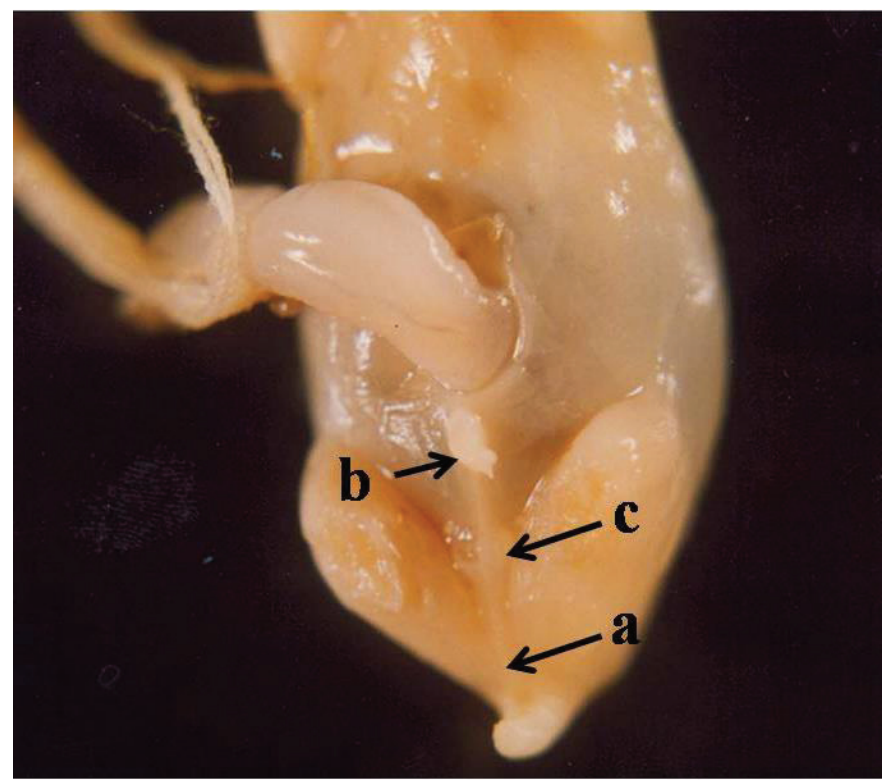

Fig (4): Photograph of a 50-day-old goat foetus (ventral view) showing distinct anogenital raphe (a), glans penis (b) and scrotal swellings (c). 


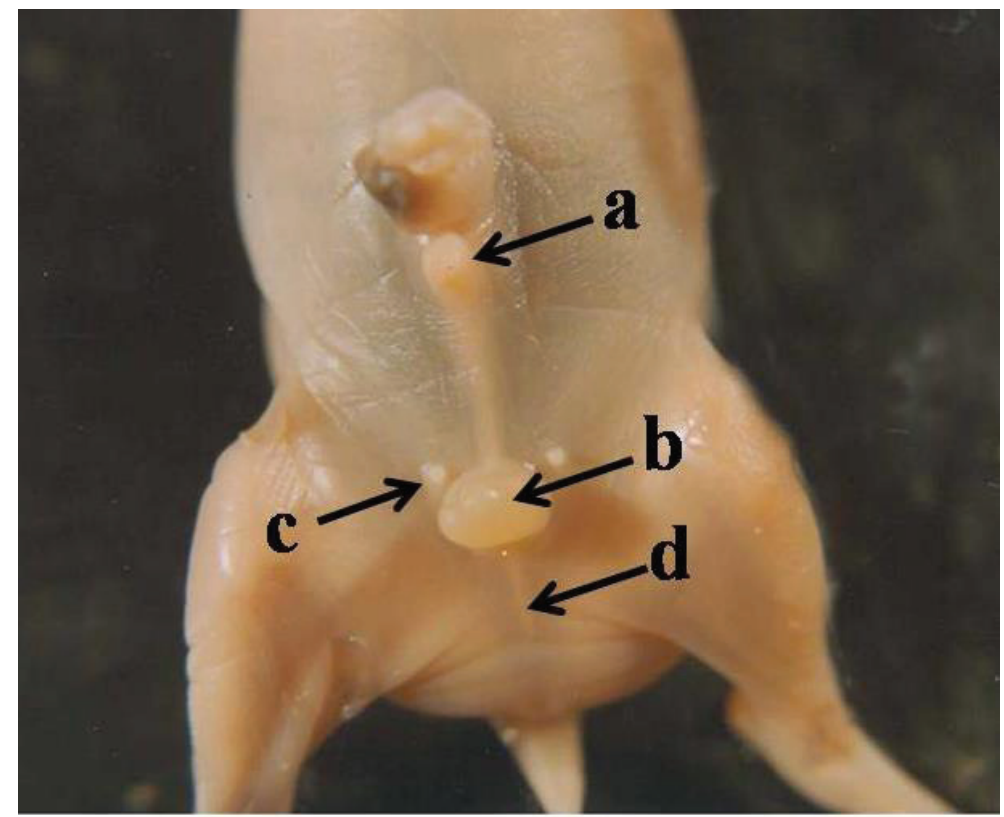

Fig (5): Photograph of a 72-day-old goat foetus showing the glans reached the close to umbilicus (a), scrotum (b), rudimentary teat (c), and ano-genital raphe (d).

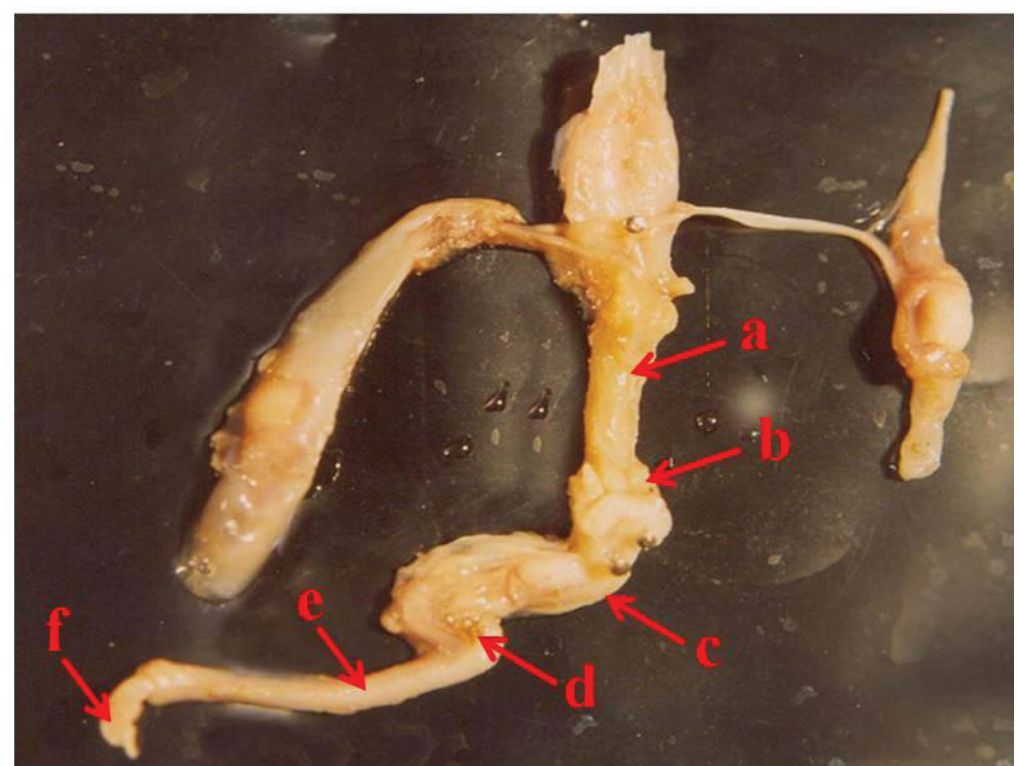

Fig (6): Photograph of male genital organs of 125-day-old goat foetus showing pelvic urethra (a), bulbourethral gland (b), retractor penis (c), sigmoid flexure (d), body of penis (e), and glans of penis (f). 